Check for updates

Cite this: RSC Adv., 2017, 7, 30080

Received 21st April 2017

Accepted 4th June 2017

DOI: $10.1039 / c 7 r a 04498 d$

rsc.li/rsc-advances

\section{Hydrogenation/oxidation induced efficient reversible color switching between methylene blue and leuco-methylene blue $\uparrow$}

\author{
Ya-Nan Liu, Xiao Zhou, Xin Wang, Kuang Liang, Zheng-Kun Yang, Cong-Cong Shen, \\ M. Imran, Shafaq Sahar and An-Wu Xu (ID *
}

In this paper, we present the use of graphitic carbon nitride $\left(g-C_{3} N_{4}\right)$ supported palladium nanoparticles $\left(\mathrm{Pd} / \mathrm{g}-\mathrm{C}_{3} \mathrm{~N}_{4}\right)$ for reversible color switching of methylene blue (MB). $\mathrm{g}-\mathrm{C}_{3} \mathrm{~N}_{4}$ with a high polymeric degree could improve the dispersity of $\mathrm{Pd}$ nanoparticles, contributing to fast color switching of $\mathrm{MB}$ as the agglomeration of metal nanoparticles is significantly prevented. Moreover, strong metal-support interaction (SMSI) between $\mathrm{Pd}$ nanoparticles and $\mathrm{g}-\mathrm{C}_{3} \mathrm{~N}_{4}$ support promotes the adsorption and subsequent dissociation of molecular hydrogen and oxygen, thus leading to efficient reversible conversion between $\mathrm{MB}$ and leuco-methylene blue (LMB). Our obtained $\mathrm{Pd} / \mathrm{g}-\mathrm{C}_{3} \mathrm{~N}_{4}$ nanocatalyst exhibits outstanding hydrogenation activity of blue MB to colorless LMB with a turnover frequency as high as 165 $\mathrm{h}^{-1}$ at room temperature, moreover, colorless LMB can quickly switch back to MB upon exposing the same reaction system to oxygen for oxidation. It is noted that our color switching system exhibits remarkable reversibility and stability without obvious fatigue even after 10 consecutive cycles. This novel redox-driven reversible color switching system could find potential in food packaging, sensing and organic transformations.

\section{Introduction}

Over the last few decades, materials have become increasingly important in the development of human society. One of the key innovations in this field is the emergence of color switching materials that react upon exposure to certain stimuli. Colorswitching materials have attracted a great deal of attention due to their application prospects in rewritable paper, sensors, optical data storage and security feature technologies. ${ }^{1-4}$ Significant efforts were previously devoted to develop various systems with improved stability to enhance switching rates. Pal et al. have reported reversible color switching of organic redox dyes over various catalysts. In these cases, the color changes are strongly influenced by the $\mathrm{pH}$ of the solution or the type of reducing agent contained in the system..$^{5-10} \mathrm{With}$ the continuing search for color switching system, the self-assembled monolayer of azobenzene on Au (111) shows good reversibility for photoinduced cis-trans photoisomerization; polymer coated $\mathrm{TiO}_{2}$ nanocrystals also prove to be an efficient color switching system without relying on external sacrificial electron donors. ${ }^{11,12}$ However, the chromophores experience competing

Division of Nanomaterials and Chemistry, Hefei National Laboratory for Physical Sciences at Microscale Department, University of Science and Technology of China, Hefei 230026, P. R. China.E-mail: anwuxu@ustc.edu.cn

$\dagger$ Electronic supplementary information (ESI) available: Experimental details, material characterizations and additional figures. See DOI: $10.1039 / \mathrm{c} 7 \mathrm{ra04498d}$ thermal back relaxation and sometimes other side reactions for reversible color switching, and then hinder the further application of color switching system. Therefore, for a clean and reversible color switching system, molecular hydrogen, oxygen, suitable dyes and efficient catalysts are required.

Methylene blue (MB), a positively charged heterocyclic aromatic thiazine dye, has long been used as staining agent in industry. ${ }^{13}$ In reducing environment, methylene blue can be reduced to colorless leuco-methylene blue (LMB) through hydrogenation reaction, which can switch back to initial blue color by oxidative dehydrogenation upon exposure to oxidizing environment.

Recent years have witnessed a growing interest in palladium based nanomaterials due to their exceptional properties and potential applications in hydrogenation and oxidation reactions. ${ }^{14,15}$ Meanwhile, it is well established in the literature that the nature of support plays a key role in the catalytic performance of Pd-containing catalyst. ${ }^{16}$ For a given reaction, the activity, selectivity and stability of the catalyst could be improved by use of an appropriate support. Recently, graphitic carbon nitride $\left(\mathrm{g}-\mathrm{C}_{3} \mathrm{~N}_{4}\right)$, a metal-free conjugated polymer, has attracted ever-growing attention in recent years. ${ }^{17,18}$ g- $\mathrm{C}_{3} \mathrm{~N}_{4}$ may find a much wider range of applications as compared to carbon materials due to the incorporation of nitrogen atoms in the carbon, which can improve its chemical, electrical and functional properties. ${ }^{19}$ The structure of $\mathrm{g}-\mathrm{C}_{3} \mathrm{~N}_{4}$ is a two-dimensional (2D) framework of tri-s-triazine connected via tertiary amines, 
which endows its high thermal and chemical stability. ${ }^{20}$ Based on the specific properties of $\mathrm{g}-\mathrm{C}_{3} \mathrm{~N}_{4}$, our aim is to use g- $\mathrm{C}_{3} \mathrm{~N}_{4}$ as a support to load noble metal nanoparticles, which not only stabilizes noble metal nanoparticles against aggregation, but also induces new physicochemical properties due to the synergistic effect and strong metal-support interaction (SMSI) between noble metal nanoparticles and $\mathrm{g}-\mathrm{C}_{3} \mathrm{~N}_{4}$, resulting in the enhancement of the performance of nanocomposites. ${ }^{15,21-23}$ Therefore, Pd supported on $\mathrm{g}-\mathrm{C}_{3} \mathrm{~N}_{4}$ material could be a nice candidate and hold great potential in catalytic applications for hydrogenation and oxidative dehydrogenation reactions in redox dye based color switching system.

In this study, we report the use of highly dispersed palladium nanoparticles supported onto $\mathrm{g}-\mathrm{C}_{3} \mathrm{~N}_{4}$ nanosheets for efficient reversible color switching of methylene blue (MB). The obtained $\mathrm{Pd} / \mathrm{g}-\mathrm{C}_{3} \mathrm{~N}_{4}$ catalyst can rapidly bleach the blue color of $\mathrm{MB}$ by hydrogenation process with 1 bar hydrogen, while the colorless leuco-methylene blue (LMB) can quickly switch back to original blue color (MB) through oxidative dehydrogenation by 1 bar oxygen. This one-pot hydrogenation/oxidation color switching system can now be enabled efficiently without relying on other complicated stimuli. Finally, based on experimental results, a possible hydrogenation/oxidation reaction mechanism is proposed.

\section{Results and discussion}

g- $\mathrm{C}_{3} \mathrm{~N}_{4}$ was synthesized from dicyandiamide by heat treatment, and $\mathrm{Pd} / \mathrm{g}-\mathrm{C}_{3} \mathrm{~N}_{4}$ nanocatalyst was prepared by impregnation and $\mathrm{H}_{2}$ reduction (see Experimental). The X-ray diffraction (XRD) patterns of g- $\mathrm{C}_{3} \mathrm{~N}_{4}$ and $\mathrm{Pd} / \mathrm{g}-\mathrm{C}_{3} \mathrm{~N}_{4}$ samples are shown in Fig. 1. For bare $\mathrm{g}-\mathrm{C}_{3} \mathrm{~N}_{4}$, the XRD pattern displays two pronounced diffraction peaks; one peak at $13.10^{\circ}$ is associated with the characteristic inter-layer structural packing motif of tri-striazine units, and the other peak at $27.39^{\circ}$ is ascribed to the interlayer stacking of conjugated aromatic system. ${ }^{24}$ After Pd nanoparticles (NPs) loading on $\mathrm{g}-\mathrm{C}_{3} \mathrm{~N}_{4}$ nanosheets, a weak peak at $40.16^{\circ}$ is observed from XRD pattern, which is readily assigned to the (111) plane of Pd. The morphology and structure of obtained $\mathrm{Pd} / \mathrm{g}-\mathrm{C}_{3} \mathrm{~N}_{4}$ were further investigated by

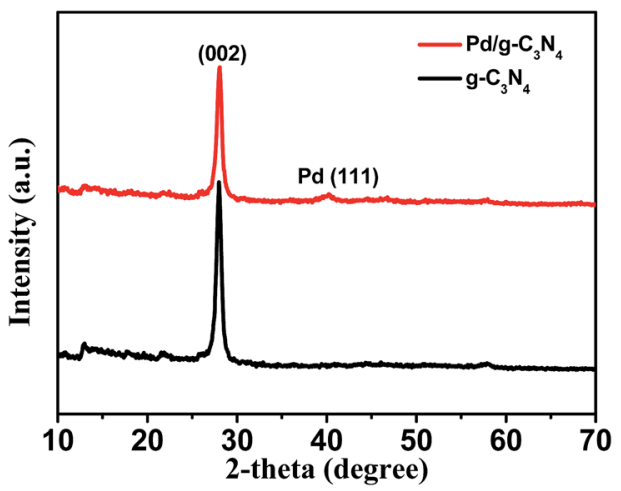

Fig. 1 XRD patterns of as-synthesized $g-C_{3} N_{4}$ and $P d / g-C_{3} N_{4}$ samples. transmission electron microscopy (TEM) and high resolution TEM (HRTEM). As shown in Fig. S1, $\uparrow$ The as-synthesized g- $\mathrm{C}_{3} \mathrm{~N}_{4}$ displays free-standing 2D lamellar structure. The HRTEM image furtherreveals the formation of $\mathrm{Pd} / \mathrm{g}-\mathrm{C}_{3} \mathrm{~N}_{4}$ nanocatalyst, the ultra small Pd NPs with an average size of $c a .5 .07 \mathrm{~nm}$ are uniform dispersed on the surface of $\mathrm{g}-\mathrm{C}_{3} \mathrm{~N}_{4}$ nanosheets (Fig. 2a and b). Fig. $2 \mathrm{c}$ presents the HRTEM image of a single particle Pd NP. The contrast line profile is plotted under the corresponding image (see Fig. 2d). The average $d$-spacing distance is measured to be $\sim 0.23 \mathrm{~nm}$, assigned to the (111) planes of Pd. All these observations demonstrate the formation of Pd NPs on g- $\mathrm{C}_{3} \mathrm{~N}_{4}$ nanosheets. In addition, the actual Pd weight content of Pd/g$\mathrm{C}_{3} \mathrm{~N}_{4}$ sample was determined to be $1.78 \mathrm{wt} \%$ by inductivelycoupled plasma mass spectrometry (ICP-MS) and is close to the nominal content in the experiment.

To further reveal information about the oxidization states and the compositions of obtained $\mathrm{Pd} / \mathrm{g}-\mathrm{C}_{3} \mathrm{~N}_{4}$ sample, X-ray photoelectron spectroscopy (XPS) measurements were performed. The representative XPS survey scan (Fig. 3a) exhibits the existence of $\mathrm{C}, \mathrm{N}$ and Pd elements. The high resolution $\mathrm{C} 1 \mathrm{~s}$ spectrum shows two peaks at binding energy of $284.95 \mathrm{eV}$ and $288.30 \mathrm{eV}$ (Fig. 3b). The weaker one centered at $284.95 \mathrm{eV}$ can be attributed to $\mathrm{C}-\mathrm{C}$ coordination, while the other peak located at $288.30 \mathrm{eV}$ is assigned to the carbon atom bonded to three nitrogen atoms $(\mathrm{C}-\mathrm{N}-\mathrm{C})$ in $\mathrm{g}-\mathrm{C}_{3} \mathrm{~N}_{4}$ lattice. ${ }^{25}$ From $\mathrm{N} 1 \mathrm{~s}$ spectrum (Fig. 3c), it can be seen that the broad peak of $\mathrm{N} 1 \mathrm{~s}$ is deconvoluted into three Gaussian components having centres at $398.75 \mathrm{eV}, 399.40 \mathrm{eV}$ and $401.15 \mathrm{eV}$. The component at $398.75 \mathrm{eV}$ is due to the $\mathrm{C}-\mathrm{N}-\mathrm{C}$ bonding, while the components at $399.40 \mathrm{eV}$ and $401.15 \mathrm{eV}$ are ascribed to the tertiary nitrogen $\mathrm{N}-$ $(\mathrm{C})_{3}$ and $\mathrm{N}-\mathrm{H}$ respectively. ${ }^{26,27}$ These $\pi$-bonded planar C-N-Clayers as well as their incompletely condensed amino groups in $\mathrm{g}^{-} \mathrm{C}_{3} \mathrm{~N}_{4}$ are conducive to stabilize highly dispersed Pd NPs and prevent their aggregation and oxidation..$^{15}$ The $3 \mathrm{~d}$ XPS spectrum of Pd NPs supported on carbon nitride presents a doublet corresponding to $\mathrm{Pd} 3 \mathrm{~d}_{5 / 2}$ and $\mathrm{Pd} 3 \mathrm{~d}_{3 / 2}$ (Fig. $3 \mathrm{~d}$ ). The deconvoluted
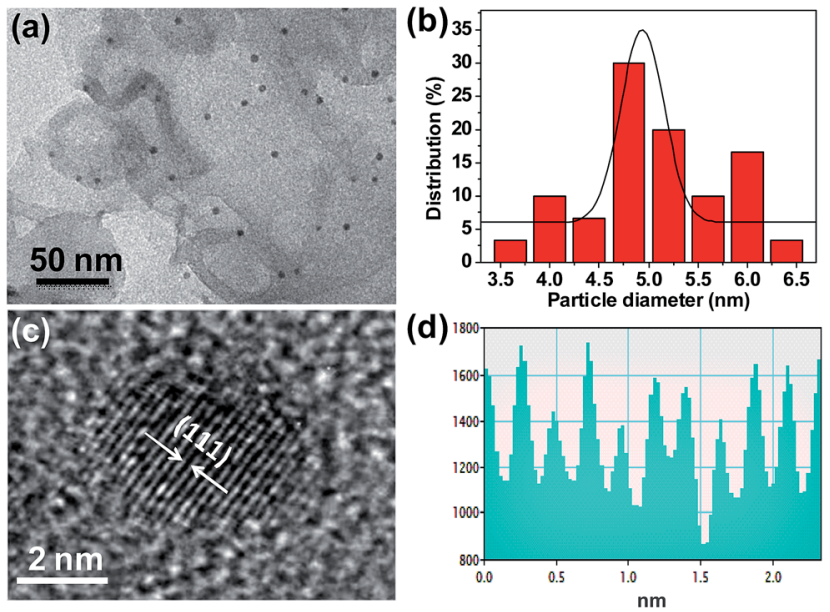

Fig. 2 TEM image of $\mathrm{Pd} / \mathrm{g}-\mathrm{C}_{3} \mathrm{~N}_{4}(\mathrm{a})$, and the size distribution of $\mathrm{Pd}$ NPs (b), HRTEM image (c) and contrast intensity profile indicates the lattice parameter of Pd (d). 

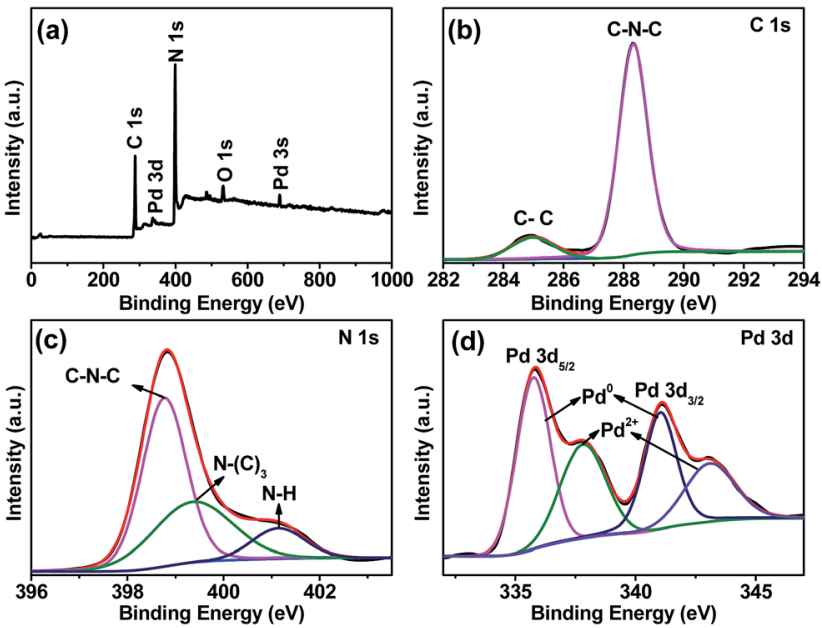

Fig. 3 XPS survey spectrum of as-prepared $\mathrm{Pd} / \mathrm{g}-\mathrm{C}_{3} \mathrm{~N}_{4}$ (a), and highresolution XPS spectra of $C 1 \mathrm{~s}(\mathrm{~b}), \mathrm{N} 1 \mathrm{~s}$ (c) and Pd $3 d$ (d).

Gaussian components at $335.75 \mathrm{eV}$ and $341.05 \mathrm{eV}$ are assigned to metallic $\mathrm{Pd}^{0}$, in agreement with XRD result. While the components at binding energy of $337.85 \mathrm{eV}$ and $343.15 \mathrm{eV}$ are attributed to $\mathrm{Pd}^{2+} \cdot{ }^{28,29}$ XPS data reveals that $\mathrm{Pd}^{0}(56.67 \%)$ is the main species of Pd on the surface of g- $\mathrm{C}_{3} \mathrm{~N}_{4}$, as clearly observed from TEM images. Notably, the corresponding peaks of $\mathrm{Pd}^{0}$ in $\mathrm{Pd} / \mathrm{g}-\mathrm{C}_{3} \mathrm{~N}_{4}$ sample shift to higher-energy side to a certain extent (about $0.9 \mathrm{eV}$ ) as compared to bare $\mathrm{Pd}^{0}{ }^{30}$ This binding energy shift is due to a fact that strong metal support interaction (SMSI) occurs between Pd NPs and g- $\mathrm{C}_{3} \mathrm{~N}_{4}$ support, ${ }^{31}$ which is beneficial to the activation of $\mathrm{H}_{2}$ and $\mathrm{O}_{2}$, thus boosts the catalytic performance. The existence of $\mathrm{Pd}^{2+}$ may be attributed to the following reasons: (a) the Pd-N bond formed at the interface of $\mathrm{Pd} / \mathrm{g}-\mathrm{C}_{3} \mathrm{~N}_{4}$; (b) the reduction of $\mathrm{Pd}^{2+}$ was not entirely completed; (c) the external metal $\mathrm{Pd}^{0}$ is likely oxidized to $\mathrm{Pd}^{2+}$ at ambient conditions. ${ }^{28,32,33}$

The reversible color switching was conducted in one-pot reaction system, MB was used as a model redox dye to evaluate the catalytic activities of $\mathrm{Pd} / \mathrm{g}-\mathrm{C}_{3} \mathrm{~N}_{4}$ catalyst. The hydrogenation of $\mathrm{MB}$ was performed over $\mathrm{Pd} / \mathrm{g}-\mathrm{C}_{3} \mathrm{~N}_{4}$ catalysts under a hydrogen pressure of $1 \mathrm{bar}$ at room temperature. In the process of hydrogenation, the color of the aqueous MB solution rapidly changed from blue to colorless with increasing the
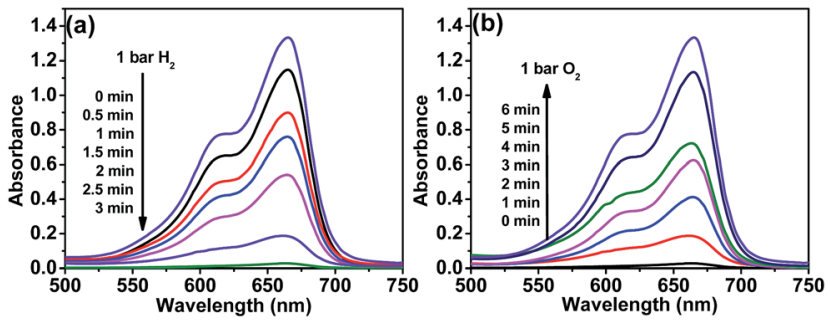

Fig. 4 The color switching of the $\mathrm{Pd} / \mathrm{g}-\mathrm{C}_{3} \mathrm{~N}_{4} / \mathrm{MB} / \mathrm{HEC}$ system: UV/vis spectra showing the decoloration process under 1 bar $\mathrm{H}_{2}$ (a) and UV/ vis spectra showing the recoloration process under 1 bar $\mathrm{O}_{2}$ (b) at room temperature. reaction time and completely disappeared after $3 \mathrm{~min}$, corresponding to the reduction of MB to LMB. Fig. 4a shows the time dependent UV/vis spectra of the reaction solution, the absorption peak of $\mathrm{MB}$ at $664 \mathrm{~nm}$ decreases in intensity within a short period of time in the presence of hydrogen $\left(\mathrm{H}_{2}\right)$. The outstanding hydrogenation activity of $\mathrm{Pd} / \mathrm{g}-\mathrm{C}_{3} \mathrm{~N}_{4}$ is attributed to the synergistic effect of active Pd species and g- $\mathrm{C}_{3} \mathrm{~N}_{4}$ support. g$\mathrm{C}_{3} \mathrm{~N}_{4}$ nanosheets not only stabilize Pd NPs against aggregation, but also enhance the adsorption of $\pi$-conjugated MB substrate via the $\pi-\pi$ interaction. The hydrogenation of $\mathrm{MB}$ over $\mathrm{Pd} / \mathrm{g}$ $\mathrm{C}_{3} \mathrm{~N}_{4}$ hybrid catalyst was assessed by the turnover frequency (TOF, defined as the moles of MB molecules per mole of Pd catalyst per hour), which was calculated to be as high as 165 $\mathrm{h}^{-1}$.

After the completion of hydrogenation reaction, $\mathrm{H}_{2}$ atmosphere was replaced by $\mathrm{O}_{2}$ to evaluate the oxidative dehydrogenation performance of $\mathrm{Pd} / \mathrm{g}-\mathrm{C}_{3} \mathrm{~N}_{4}$. It is noted that the LMB is spontaneously and quickly oxidized back to $\mathrm{MB}$ in the presence of $\mathrm{Pd} / \mathrm{g}-\mathrm{C}_{3} \mathrm{~N}_{4}$ when the system is exposed to oxygen or air. To make the system compatible with the needs in practical applications, hydroxyethyl cellulose (HEC) was added in the reaction system. The HEC can stabilize LMB through hydrogen bonding between the abundant - $\mathrm{OH}$ groups on HEC molecules and the $-\mathrm{N}\left(\mathrm{CH}_{3}\right)_{2}$ groups on LMB (Fig. S2 $\dagger$ ), and then efficiently slow down the fast recoloration process (oxidative dehydrogenation process) at ambient conditions. ${ }^{1}$ When the system was exposed to oxygen atmosphere of 1 bar pressure at room temperature, the absorption peak intensity of MB gradually increased and recovered to the original intensity within 6 min (Fig. 4b). The colorless solution (LMB) quickly switched back to original blue color (MB) by activated $\mathrm{O}_{2}$ over $\mathrm{Pd} / \mathrm{g}-\mathrm{C}_{3} \mathrm{~N}_{4}$. In the process of oxidative dehydrogenation, highly dispersed Pd NPs on $\mathrm{g}^{-} \mathrm{C}_{3} \mathrm{~N}_{4}$ nanosheets play a crucial role in effectively oxidizing LMB to $\mathrm{MB}$, because the adsorption and dissociation of $\mathrm{O}_{2}$ on the surface of Pd NPs is highly favorable. ${ }^{34}$

To evaluate the stability of our color switching system for potential application, the hydrogenation and oxidation processes were repeated for 10 consecutive cycles by sequentially exposing the system to hydrogen and oxygen atmosphere. The absorbance of methylene blue $(\sim 664 \mathrm{~nm})$ for 10 repeated hydrogenation/oxidative dehydrogenation cycles was plotted and shown in Fig. 5. The result demonstrates complete reversibility with only a slight decrease in absorption intensity after repeated cycles. Overall, the outstanding hydrogenation/ dehydrogenation performance makes the system suitable for potential applications due to its excellent reversibility and low environmental toxicity.

To ensure the possible use of our color switching system in practical applications, a simple lab demonstration was performed (Fig. 6). As the color switching system was exposed to hydrogen atmosphere $\left(1\right.$ bar $\left.\mathrm{H}_{2}\right)$, the color of the system changed from blue to colorless corresponding to the hydrogenation of MB to LMB. While the colorless solution was exposed to an oxidative environment $\left(1 \mathrm{bar} \mathrm{O}_{2}\right)$ in the presence of $\mathrm{Pd} / \mathrm{g}$ $\mathrm{C}_{3} \mathrm{~N}_{4}$ catalyst, the blue color gradually appeared and the system completely recovers to its pristine blue color in $6 \mathrm{~min}$, which is much faster than that without $\mathrm{Pd} / \mathrm{g}-\mathrm{C}_{3} \mathrm{~N}_{4}$ catalyst (Fig. $\mathrm{S} 3 \dagger$ ). The 


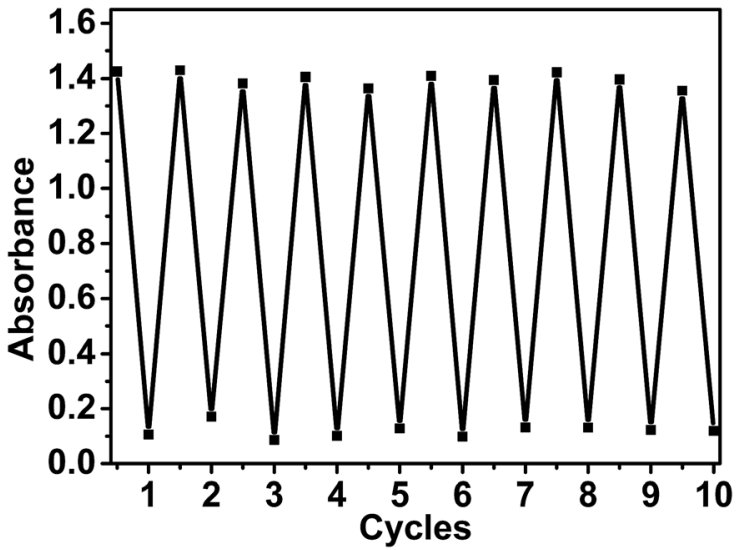

Fig. 5 The absorption intensity at about $664 \mathrm{~nm}$ of the mixture recorded continuously in the switching cycles between blue color and colorless states.

principle behind the application is that the oxidation of LMB is stopped in the absence of oxygen, but it can be rapidly reoxidized back to its original blue color (MB) in the existence of oxygen and $\mathrm{Pd} / \mathrm{g}-\mathrm{C}_{3} \mathrm{~N}_{4}$ catalyst. The inclusion of this color switching system in food packaging could serve as oxygen indicator to ensure the packaging is properly sealed and the quality of food can be guaranteed..$^{35}$ This color switching system can also be used as security ink for anti-counterfeiting, information coding applications. The information can be written by using aqueous dispersion of $\mathrm{Pd} / \mathrm{g}-\mathrm{C}_{3} \mathrm{~N}_{4} / \mathrm{MB} / \mathrm{HEC}$ which will become colorless after hydrogenation process, while the visible images or words can be regenerated from the printed ink upon exposure to oxidative environment for a period of time.

Based on the above results, a possible mechanism of one-pot reversible color switching over $\mathrm{Pd} / \mathrm{g}-\mathrm{C}_{3} \mathrm{~N}_{4}$ is proposed (Scheme 1)..$^{14,15,36-38}$ Depending on the nature of the catalyst's active sites, $\mathrm{MB}$ molecules can interact with $-\mathrm{NH}$ and $-\mathrm{NH}_{2}$ groups on the surface of $\mathrm{g}^{-} \mathrm{C}_{3} \mathrm{~N}_{4}$ through strong $\mathrm{S} \cdots \mathrm{H}-\mathrm{N}$ or $\pi \cdots \pi$ interactions. $^{36,39}$ The $\pi \cdots \pi$ interaction between the $\pi$ electron of graphitic carbon nitride and the aromatic ring of $\mathrm{MB}$, is beneficial for adsorption of $\mathrm{MB}$ molecules on the surface of $\mathrm{g}-\mathrm{C}_{3} \mathrm{~N}_{4}$. It is well documented that altering the electronic structure of metal nanocatalyst is an effective strategy to optimize the catalytic performance. ${ }^{40}$ For Pd/g- $\mathrm{C}_{3} \mathrm{~N}_{4}$ catalyst, the nitrogen

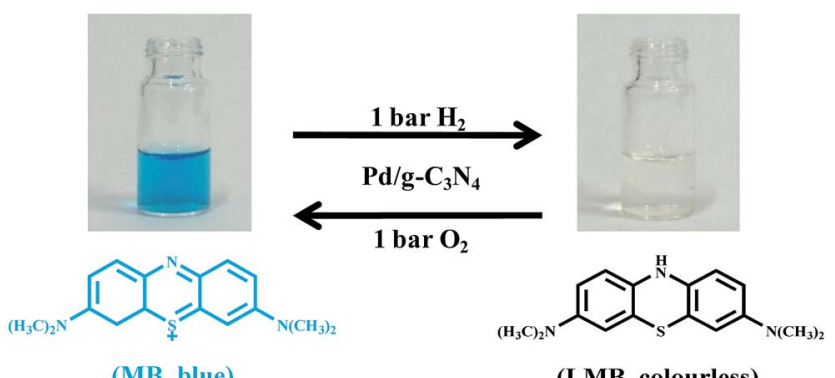

Fig. 6 Reversible color switching of $M B / L M B$ with $\mathrm{Pd} / \mathrm{g}-\mathrm{C}_{3} \mathrm{~N}_{4}$ as catalyst at room temperature.

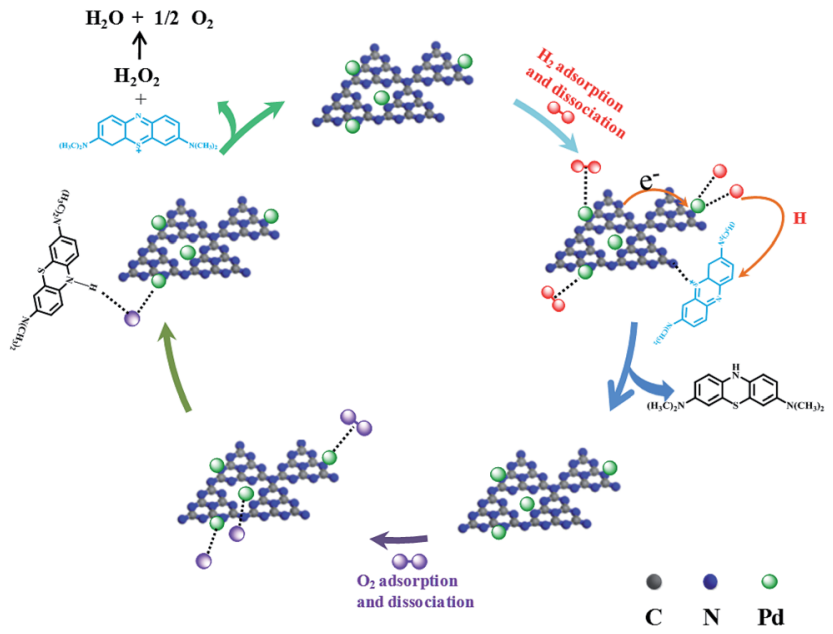

Scheme 1 Proposed reaction processes of color switching of methylene blue over $\mathrm{Pd} / \mathrm{g}-\mathrm{C}_{3} \mathrm{~N}_{4}$ nanocatalyst.

atoms in $\mathrm{g}-\mathrm{C}_{3} \mathrm{~N}_{4}$ could enrich the electron density of the metallic Pd due to the interfacial polarization between Pd and g$\mathrm{C}_{3} \mathrm{~N}_{4},{ }^{41}$ consequently accelerating the reactions of color switching. As shown in Scheme 1, MB can easily adsorbed on the surface of the catalyst via the $\pi \cdots \pi$ interaction, molecular hydrogen would initially bind to the atoms of Pd nanoparticles through its $\mathrm{H}-\mathrm{H} \sigma$-bond and then undergo homolytic dissociation into $\mathrm{H}$ atoms with partially negative charge $\left(\mathrm{H}^{\delta-}\right) \cdot{ }^{42,43}$ The electron-electron repulsion effect in $\mathrm{H}^{\delta-}$ and electron-rich Pd NPs is beneficial for the rapid desorption of $\mathrm{H}^{\delta-}$. Subsequently, MB molecules can efficiently react with the active $\mathrm{H}$ and LMB formed via the synergistic interactions between Pd NPs and g$\mathrm{C}_{3} \mathrm{~N}_{4}$ support. Meanwhile, Pd is also an efficient catalyst for oxidative reactions in the presence of molecular $\mathrm{O}_{2}$. This reaction proceeds through the following way: $\mathrm{O}_{2}$ is first adsorbed on the surface of Pd NPs, and electron transfer from Pd surface to the ground state of $\mathrm{O}_{2}$ occurs, the change of the charge density on Pd surface is expected to form the Pd-O bond..$^{44}$ Then, the hydrogen atom of $\mathrm{N}-\mathrm{H}$ bond in LMB interacts with the negatively charged oxygen atoms, leading to fast oxidation of LMB to MB. The reaction of hydride species with the activated oxygen regenerates $\mathrm{Pd}^{0}$ species along with the formation of $\mathrm{H}_{2} \mathrm{O}_{2}$; and $\mathrm{H}_{2} \mathrm{O}_{2}$ eventually decomposes to $\mathrm{O}_{2}$ and $\mathrm{H}_{2} \mathrm{O}$. In Pd/g- $\mathrm{C}_{3} \mathrm{~N}_{4}$ hybrid structure, the loaded $\mathrm{Pd}$ atoms are preferentially deposited on nitrogen sites, which can increase the electron density on Pd surface and promotes the oxidation reaction, resulting in an increased recoloration reaction rates. ${ }^{41}$ In this work, taken together, strong metal support interaction between metallic Pd and $\mathrm{g}-\mathrm{C}_{3} \mathrm{~N}_{4}$ support plays an important role in highly efficient reversible color switching of methylene blue/ leuco-methylene blue.

\section{Conclusions}

In this study, $\mathrm{Pd} / \mathrm{g}-\mathrm{C}_{3} \mathrm{~N}_{4}$ nanocatalyst has been successfully synthesized, and used for one-pot reversible hydrogenation and oxidation reactions. g- $\mathrm{C}_{3} \mathrm{~N}_{4}$ nanosheets with a higher polymeric 
degree could improve the dispersity and stability of Pd nanoparticles. Methylene blue is used as model redox dye to investigate the hydrogenation and oxidative dehydrogenation reactions. The obtained $\mathrm{Pd} / \mathrm{g}-\mathrm{C}_{3} \mathrm{~N}_{4}$ shows superior hydrogenation of $\mathrm{MB}$ to colorless LMB which can rapidly switch back to MB by re-oxidation process in the presence of oxygen or air under ambient conditions. The strong metal support interaction between Pd NPs and graphitic carbon nitride boosts the adsorption and subsequent dissociation of hydrogen and oxygen molecules, resulting in highly efficient reversible color switching between MB and LMB. More importantly, the Pd/g$\mathrm{C}_{3} \mathrm{~N}_{4} / \mathrm{MB} / \mathrm{HEC}$ switching system exhibit remarkable reversibility and durability as the absorption intensity of $\mathrm{MB}$ at $664 \mathrm{~nm}$ shows only a slight decrease even after 10 consecutive switching cycles. Compared to the previous color switching systems, the current system has same advantages in terms of high efficiency, recyclability and easy preparation, and could provide opportunities in food packaging, printing inks for writing and erasing paper, and so on.

\section{Acknowledgements}

The special funding support from the National Natural Science Foundation of China (51572253, 21271165), Scientific Research Grant of Hefei Science Center of CAS (2015SRG-HSC048), and cooperation between NSFC and Netherlands Organization for Scientific Research (51561135011) is acknowledged.

\section{References}

1 W. S. Wang, N. Xie, L. He and Y. D. Yin, Nat. Commun., 2014, 5, 5459.

2 H. L. Dong, H. F. Zhu, Q. Meng, X. Gong and W. P. Hu, Chem. Soc. Rev., 2012, 41, 1754-1808.

3 Y. D. Liu, X. G. Han, L. He and Y. D. Yin, Angew. Chem., Int. Ed., 2012, 51, 6373-6377.

4 Y. Galagana and W. F. Su, J. Photochem. Photobiol., A, 2008, 195, 378-383.

5 M. Basu, A. K. Sinha, M. Pradhan, S. Sarkar, A. Pal, C. Mondal and T. Pal, J. Phys. Chem. C, 2012, 116, 25741-25747.

6 C. Ray, S. Dutta, S. Sarkar, R. Sahoo, A. Roy and T. Pal, RSC Adv., 2013, 3, 24313-24320.

7 J. Pal, M. Ganguly, S. Dutta, C. Mondal, Y. Negishi and T. Pal, CrystEngComm, 2014, 16, 883-893.

8 S. Pande, S. Jana, S. Basu, A. K. Sinha, A. Datta and T. Pal, J. Phys. Chem. C, 2008, 112, 3619-3626.

9 T. Pal, S. De, N. R. Jana, N. Pradhan, R. Mandal and A. Pal, Langmuir, 1998, 14, 4724-4730.

10 T. Pal and R. Chaiti, Metal Nanoparticles for Catalysis, 2014, vol. 17, pp. 203-218.

11 H. Jacob, S. Ulrich, U. Jung, S. Lemke, T. Rusch, C. Schutt, F. Petersen, T. Strunskus, O. Magnussen, R. Herges and F. Tuczek, Phys. Chem. Chem. Phys., 2014, 16, 22643-22650.

12 W. S. Wang, Y. F. Ye, J. Feng, M. F. Chi, J. H. Guo and Y. D. Yin, Angew. Chem., Int. Ed., 2015, 127, 1337-1342.

13 M. Wainwright, M. N. Byrne and M. A. Gattrell, J. Photochem. Photobiol., B, 2006, 84, 227-230.
14 F. F. Wang, Z. S. Lu, L. Yang, Y. X. Zhang, Q. H. Tang, Y. M. Guo, X. M. Ma and Z. X. Yang, Chem. Commun., 2013, 49, 6626-6628.

15 Y. Wang, J. Yao, H. R. Li, D. S. Su and M. Antonietti, J. Am. Chem. Soc., 2011, 133, 2362-2365.

16 Z. L. Zheng, C. Sun, R. Dai, S. Y. Wang, X. Wu, X. An and X. M. Xie, Catal. Sci. Technol., 2016, 6, 6472-6475.

17 Y. Zheng, L. H. Lin, B. Wang and X. C. Wang, Angew. Chem., Int. Ed., 2015, 54, 12868-12884.

18 G. G. Liu, T. Wang, H. B. Zhang, X. G. Meng, D. Hao, K. Chang, P. Li, T. Kako and J. H. Ye, Angew. Chem., Int. Ed., 2015, 54, 13561-13565.

19 F. Raziq, C. M. Li, M. Humayun, Y. Qu, A. Zada, H. T. Yu and L. Q. Jing, Mater. Res. Bull., 2015, 70, 494-499.

20 Y. Wang, X. C. Wang and M. Antonietti, Angew. Chem., Int. Ed., 2012, 51, 68-89.

21 S. J. Liang, Y. Z. Xia, S. Y. Zhu, S. Zheng, Y. H. He, J. H. Bi, M. H. Liu and L. Wu, Appl. Surf. Sci., 2015, 358, 304-312.

22 F. F. Wang, S. Shao, C. L. Liu, C. L. Xu, R. Z. Yang and W. S. Dong, Chem. Eng. J., 2015, 264, 336-343.

23 S. J. Tauster, Acc. Chem. Res., 1987, 20, 389-394.

24 F. Goettmann, A. Fischer, M. Antonietti and A. Thomas, Angew. Chem., Int. Ed., 2006, 45, 4467-4471.

25 S. X. Min and G. X. Lu, J. Phys. Chem. C, 2012, 116, 1964419652.

26 E. Raymundo-Piñero, D. Cazorla-Amorós, A. Linares-Solano, J. Find, U. Wild and R. Schlögl, Carbon, 2002, 40, 597-608.

27 D. L. Jiang, L. L. Chen, J. M. Xie and M. Chen, Dalton Trans., 2014, 43, 4878-4885.

28 J. W. Sun, Y. S. Fu, G. Y. He, X. Q. Sun and X. Wang, Catal. Sci. Technol., 2014, 4, 1742-1748.

29 S.-H. Oh and G. B. Hoflund, J. Phys. Chem. A, 2006, 110, 7609-7613.

30 C. D. Wagner, W. M. Riggs, L. E. Davis, J. F. Moulder and G. E. Muilenberg, Handbook of X-ray Photoelectron Spectroscopy, 1979, p. 55.

31 A. Y. Klyushin, M. T. Greiner, X. Huang, T. Lunkenbein, X. Li, O. Timpe, M. Friedrich, M. Hävecker, A. Knop-Gericke and R. Schlögl, ACS Catal., 2016, 6, 3372-3380.

32 B. J. Hu, T. B. Wu, K. L. Ding, X. S. Zhou, T. Jiang and B. X. Han, J. Phys. Chem. C, 2010, 114, 3396-3400.

33 V. B. Parambhath, R. Nagar and S. Ramaprabhu, Langmuir, 2012, 28, 7826-7833.

34 R. J. Madix, Science, 1986, 233, 1159-1166.

35 M. Imran, A. B. Yousaf, X. Zhou, K. Liang, Y.-F. Jiang and A.-W. Xu, Langmuir, 2016, 32, 8980-8987.

36 Y. T. Gong, P. F. Zhang, X. Xu, Y. Li, H. R. Li and Y. Wang, J. Catal., 2013, 297, 272-280.

37 S. K. Konda and A. C. Chen, Mater. Today, 2016, 19, 100-108. 38 C. J. Heard, S. Siahrostami and H. Grönbeck, J. Phys. Chem. C, 2016, 120, 995-1003.

39 E. Haque, J. W. Jun, S. N. Talapaneni, A. Vinu and S. H. Jhung, J. Mater. Chem., 2010, 20, 10801-10803.

40 G. X. Chen, C. F. Xu, X. Q. Huang, J. Y. Ye, L. Gu, G. Li, Z. C. Tang, B. H. Wu, H. Y. Yang, Z. P. Zhao, Z. Y. Zhou, G. Fu and N. F. Zheng, Nat. Mater., 2016, 15, 564-569. 
41 P. F. Zhang, Y. T. Gong, H. R. Li, Z. R. Chen and Y. Wang, Nat. Commun., 2013, 4, 1593.

42 S. Syrenova, C. Wadell, F. A. A. Nugroho, T. A. Gschneidtner, Y. A. Diaz Fernandez, G. Nalin, D. Switlik, F. Westerlund, T. J. Antosiewicz, V. P. Zhdanov, K. Moth-Poulsen and C. Langhammer, Nat. Mater., 2015, 14, 1236-1244.
43 P. X. Liu, Y. Zhao, R. X. Qin, S. G. Mo, G. X. Chen, L. Gu, D. M. Chevrier, P. Zhang, Q. Guo, D. D. Zang, B. H. Wu, G. Fu and N. F. Zheng, Science, 2016, 352, 797-800.

44 Y. Bai, W. H. Zhang, Z. H. Zhang, J. Zhou, X. J. Wang, C. M. Wang, W. X. Huang, J. Jiang and Y. J. Xiong, J. Am. Chem. Soc., 2014, 136, 14650-14653. 